\title{
Impact of initial dialysis modality on the survival of patients with ESRD in eastern China: a propensity-matched study
}

Xi Yao ${ }^{1,2}$, Wenhua Lei ${ }^{1,2}$, Nan Shi ${ }^{1,2}$, Weiqiang Lin ${ }^{1,2}$, Xiaoying Du ${ }^{1,2}$, Ping Zhang ${ }^{1,2^{*}}$ and Jianghua Chen ${ }^{1,2^{*}}$ (D)

\begin{abstract}
Background: There are conflicting research results about the survival differences between hemodialysis(HD) and peritoneal dialysis (PD). The present study estimated the survival and the relative mortality hazard for incident HD and PD patients with end stage renal disease (ESRD) in eastern China.

Methods: This study examined a cohort of patients with ESRD who initiated dialysis therapy in Zhejiang province between Jan of 2010 and Dec of 2014, followed up until the end of 2015. PD patients were matched in a 1:1 fashion with HD patients, and Kaplan-Meier analysis was used to explore the survival of them. The Cox proportional hazard regression model was applied to identify the factors that predict survival by treatment modality. Subgroup analyses were conducted by stratifying patients according to gender, age, causes of ESRD and comorbidities.

Results: Among a total of 22,379 enrolled patients (17,029 HD patients and 5350 PD patients), 5350 matched pairs were identified, and followed for a median of 29 months ( $3 \sim 72$ months). Kaplan-Meier survival curve revealed that overall mortality rate was significantly higher in HD patients than in PD patients (log-rank test, $P<0.001$ ), after adjusting by gender, age, primary causes of ESRD and comorbidities. HD was consistently associated with an increased risk for morality compared with PD in the matched cohort (adjusted hazard ratio (AHR): 1.140, 95\%Cl: 1.023 1.271). In subgroup analyses, male, younger patients, or nondiabetic patients aged less than 65 years after adjustment of covariates, initiating with PD was associated with a significantly lower mortality compared with HD. In the multivariate Cox proportional risks model, age, diabetic nephropathy (DN), other/unknown causes of ESRD, and patients with a history of cardiovascular disease or cancer showed statistical significance in explaining survival of incident ESRD patients.
\end{abstract}

Conclusions: ESRD patients who initiated dialysis with PD yielded superior survival rates compared to HD. Increased use of PD as initial dialysis modality in ESRD patients could be encouraged in Chinese population.

Keywords: End stage renal disease (ESRD), Hemodialysis, Peritoneal dialysis, Mortality

\footnotetext{
*Correspondence: 1194076@zju.edu.cn; zjukidney@zju.edu.cn

'Kidney Disease Center, The First Affiliated Hospital, College of Medicine,

Zhejiang University, No.79 Qingchun Road, Hangzhou 310003, Zhejiang

Province, China

Full list of author information is available at the end of the article
}

(C) The Author(s). 2020 Open Access This article is licensed under a Creative Commons Attribution 4.0 International License, which permits use, sharing, adaptation, distribution and reproduction in any medium or format, as long as you give appropriate credit to the original author(s) and the source, provide a link to the Creative Commons licence, and indicate if changes were made. The images or other third party material in this article are included in the article's Creative Commons licence, unless indicated otherwise in a credit line to the material. If material is not included in the article's Creative Commons licence and your intended use is not permitted by statutory regulation or exceeds the permitted use, you will need to obtain permission directly from the copyright holder. To view a copy of this licence, visit http://creativecommons.org/licenses/by/4.0/ The Creative Commons Public Domain Dedication waiver (http://creativecommons.org/publicdomain/zero/1.0/) applies to the data made available in this article, unless otherwise stated in a credit line to the data. 


\section{Background}

Renal replacement therapy (RRT) is a usual therapy for patients suffering from end stage renal disease (ESRD), including dialysis, either hemodialysis (HD) or peritoneal dialysis (PD) and kidney transplant [1, 2]. HD and PD are the most common choices of treatment in patients suffering from ESRD, due to the organ scarcity. A substantial body of evidence has been built around the outcomes of dialysis therapies, such as survival, healthrelated quality of life, and costs [3-5]. Among them, survival is one of the most significant outcomes, and in spite of the large number of studies, there is a considerable controversy about which dialysis modality provides a better survival. Comparisons of survival for patients on PD and HD, HD has been found to be associated with better survival [6-8], whereas, several studies indicate that PD patients have a better survival during the first 1 or 2 years $[9,10]$, and some recent studies infer that the survival of PD patients equates or even surpasses the survival of HD patients [11-14]. Survival can be attributed to the therapy itself or to other factors such as age, gender, diabetes mellitus (DM), history of cardiovascular disease (CVD), comorbidity at the start of therapy. However, publications on this subject for Asian populations are scarce, especially in Mainland China.

The number of patients with ESRD continues to increase in China, the prevalence rate of chronic kidney disease (CKD) in Mainland China is reported to 10.8, and $2 \%$ of them would progress to ESRD [15]. We established a Zhejiang Renal Disease System (ZJRDS) database in 2007, which collects demographic characteristics, comorbidity, dialysis clinical data, outcome-related data of dialysis patients, and distributes information on the incidence, prevalence, treatment, morbidity, and mortality of ESRD in Zhejiang province. Thus, comparisons of survival for incident $\mathrm{HD}$ and PD patients in Zhejiang province may represent the dialysis quality in eastern China.

Randomized controlled studies are the best to compare outcomes of different dialysis modalities, however, it is difficult to achieve them in clinical practice. The propensity score matching (PSM) is a statistical technique that can reduce bias resulting from the nonrandom nature of the treatment assignment seen in observational studies [16, 17]. Therefore, we conducted a study to describe and compare the mortality among incident HD and PD patients by using a propensity score-matched cohort.

\section{Methods}

\section{Study design}

This retrospective and observational cohort study included all incident ESRD patients on HD or PD from
January 12,010 to December 31, 2014 in Zhejiang province, who had to be 18 years of age or older and had to have survived for the first 90 days on dialysis. All patients were followed until death, or switching to other renal replacement therapy (RRT), or December 31st, 2015 (the end of the study), after which survival data were censored. Patients were excluded if they had a history of kidney transplant, or no records in the dialysis start date and the initial dialysis modality, lacking demographic or clinical information. This study was approved by kidney disease center, the First Affiliated Hospital, College of Medicine, Zhejiang University. All patients allowed the usage of their clinical information, and all clinical investigations were conducted in accordance with the guidelines of Declaration of Helsinki.

\section{Study cohort}

ZJRDS database, which was established for the purposes of improving dialysis quality in Zhejiang province, and includes from 254 hemodialysis centers and 101 peritoneal dialysis centers all over our province in 2019. We obtained all data from the ZJRDS database, which is privately owned by the Zhejiang dialysis quality control committee. Initial treatment modality was assigned as follows: patients starting on $\mathrm{HD}$ were assigned $\mathrm{HD}$, whereas patients beginning with continuous ambulatory peritoneal dialysis (CAPD) or intermittent peritoneal dialysis (IPD) were classified as PD. Demographic and clinical information were collected upon entrance of patients into the cohort, including gender, age, primary causes of the ESRD (chronic glomerulonephritis (CGN), DM, hypertension, polycystic kidney disease (PKD), others or unknown causes), vascular access types and comorbidities. Comorbidities included a history of CVD (coronary artery disease, arrhythmia, congestive heart failure, peripheral vascular disease and cerebrovascular disease), chronic obstructive pulmonary disease (COPD), gastrointestinal ulcer, moderate to severe chronic liver disease and malignancy. All patients were follow-up to December 31st, 2015 , or until the occurrence of the death or censorship for all those events in which the patient was alive but could not conclude the follow-up period, including kidney transplantation, loss to follow-up and change of dialysis modality.

\section{Statistical analyses}

To address the imbalance of the effects of gender, age, causes of ESRD and comorbidity, we matched PD group with HD group using propensity scores with a one-toone nearest neighbor caliper width of 0.02 . We calculated the propensity score for PD and HD patients using a logistic regression model to estimate the probability of 
the dialysis modality on the basis of baseline variables such as age, gender, cause of the ESRD, diabetes, history of CVD, COPD, gastrointestinal ulcer, chronic liver disease and malignancy. In both the baseline and the matched cohorts, continuous variables are expressed as mean \pm SD for normally distributed data, or as median and frequency (\%) for non-normally distributed data, differences in patients' characteristics between HD and PD group were analyzed by t-test or the Mann-Whitney tests for continuous variables, whereas the $x^{2}$ test was used for categorical variables $[18,19]$. In both the entire cohort and the matched cohort, we constructed KaplanMeier curves for all-cause mortality. The risk of allcause mortality for HD patients compared with PD patients was estimated as adjusted hazard ratios (HRs) with 95\% CIs by using the multivariable Cox proportional hazards model adjusted for gender, age, sex, cause of the ESRD and comorbidity.

All statistical analyses were conducted using the SPSS (Statistical Package for Social Sciences) 22.0 software (IBM, Armonk, NY, USA) with a R software -plug-ins (R-2.15.3, https://cran.r-project.org/bin/windows/base/ old/) $[20,21]$. Statistical tests were considered significant at $P<0.05$ (two-sided).

\section{Results}

Characteristics of the patients

Between Jan of 2010 and Dec of 2014, 36,323 patients initiated dialysis in Zhejiang province. 13,944 patients were excluded, the derivation of the whole cohort is detailed in Fig. 1. (Derivation of the whole cohort). A total of 22,379 ESRD incident patients (17,029 (76.1\%) HD and 5350 (23.9\%) PD patients) were enrolled in our analysis, who were followed for a median of 29 months (range, $3 \sim 72$ months). The study subjects were more likely to be male $(57.9 \%)$ and young $(63.8 \%$ patients was under the age of 65 years old). Patients with diabetes accounted for $23.2 \%$, and 929 (4.2\%) patients had malignancy. 770 (3.5\%) patients switched modality, including 258 (1.2\%) HD switched to PD and 512 (2.3\%) PD switched to HD, 838 (3.7\%) patients were transplanted, and 2061 (9.2\%) were at lost during the following period. A comparison of demographic and clinical characteristics between the HD and PD groups showed that, on average, patients in the PD group were significantly younger (53 \pm 15 years in PD versus $58 \pm 16$ in $\mathrm{HD}, p<$ 0.001 ); had a significantly lower proportion of males (53.6\% in PD versus 59.3\% in HD, $p<0.001$ ), a history of CVD $(17.7 \%$ versus $21.2 \%, p<0.001)$, malignancy $(1.7 \%$

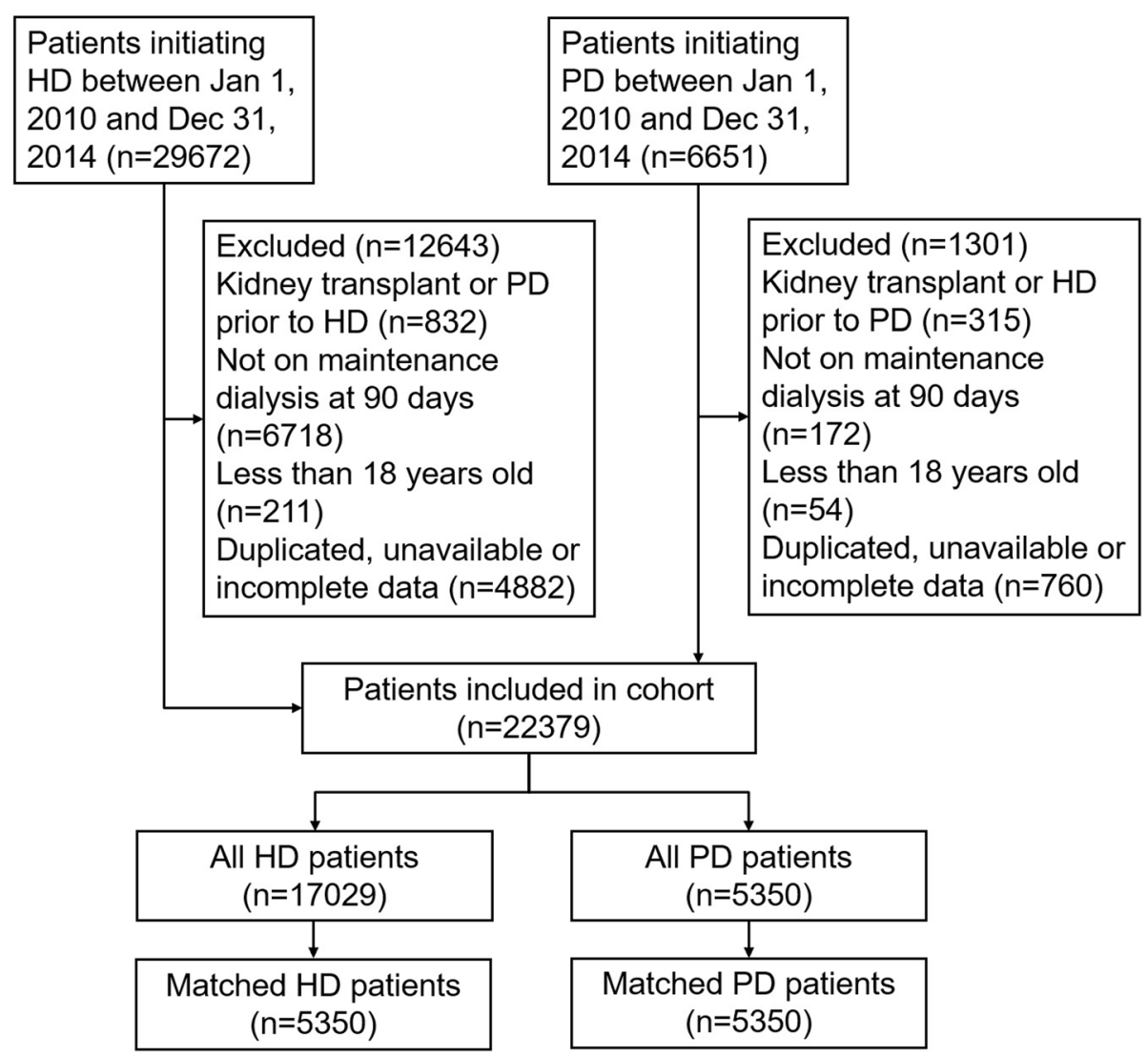

Fig. 1 Derivation of the whole cohort 
versus $4.3 \%, p<0.001)$ and $\mathrm{COPD}(0.4 \%$ versus $0.8 \%$, $p<0.05)$. In terms of the ESRD etiology, the PD group had a lower proportion of patients having diabetes as the leading cause $(8.7 \%$ in PD versus $20.7 \%$ in $\mathrm{HD}, p<$ $0.001)$, and PKD as the leading cause $(2.4 \%$ versus $4.5 \%$, $p<0.001)$ (Table 1.).

We matched 5350 pairs of patients by propensity scores, based on patients' age, gender, primary causes of ESRD and comorbidities. 11,679 HD patients were excluded, who were significantly older $(61 \pm 16$ years in excluded HD versus $53 \pm 15$ in included HD, $p<0.001$ ); had a significantly higher proportion of males $(61.5 \%$ versus $54.5 \%$, $p<0.001)$, diabetes $(6.0 \%$ versus $4.9 \%, p<0.05)$, a history of CVD (22.9\% versus $17.4 \%, p<0.001)$, malignancy $(5.6 \%$ versus $1.6 \%, p<0.001)$ and COPD $(0.9 \%$ versus $0.4 \%, p<$ 0.05). In terms of the ESRD etiology, the excluded HD group had a higher proportion of patients having diabetes as the leading cause $(26.1 \%$ versus $8.9 \%, p<0.001)$, and PKD as the leading cause $(5.5 \%$ versus $2.3 \%, p<0.001)$ (Supplemental Table 1.) The basal characteristics were different between HD patients and PD patients. Baseline characteristics for the propensity scores - matched cohorts are detailed in Table 2. As expected, baseline characteristics were well balanced between HD and PD patients in the matched cohort.
Comparisons of mortality according to dialysis modalities During the follow-up period, 3182 patients undergoing HD (18.7\%) and 602 patients undergoing PD (11.3\%) died. The overall 1-, 2-, 3-, 4-, and 5-year survival rates for HD and PD patients both in whole cohort and matched cohorts are given in Table 3. By the KaplanMeier analysis with log-rank test, statistically significant differences were found in patient survival by therapy, with a better survival for PD patients compared to HD patients (Fig. 2a. Kaplan-Meier survival curve according to the initial dialysis modality (whole cohort); log-rank test, $P<0.001)$. Using the Cox proportional hazard model adjusting by age, gender, causes of ESRD and comorbid conditions showed that PD was superior to HD as an initial modality in maintenance dialysis (HD vs PD AHR: 1.239, 95\% confidence interval (CI):1.130-1.358, $P<0.001)$.

In the matched cohorts with Kaplan-Meier plots, survival in PD patients was still better than that in HD patients (Fig. 2b. Kaplan-Meier survival curve according to the initial dialysis modality (matched cohort); logrank test, $P=0.031$ ). Cox proportional hazard model adjusting by covariates revealed that better survival seen in PD group compared with the HD group (HD vs PD AHR: $1.140 ; 95 \%$ CI: $1.023-1.271, P<0.05)$.

Table 1 Baseline characteristics of 17,029 hemodialysis (HD) and 5350 peritoneal dialysis (PD) patients

\begin{tabular}{|c|c|c|c|c|}
\hline Baseline Characteristics & $\mathrm{HD}(\boldsymbol{n}=17,029)$ & $\mathrm{PD}(\boldsymbol{n}=5350)$ & $\boldsymbol{P}$-value & Standardized differences \\
\hline Male,n(\%) & $10,096(59.3)$ & $2868(53.6)$ & $<0.001$ & 0.115 \\
\hline Age (years) & $58 \pm 16$ & $53 \pm 15$ & $<0.001$ & 0.322 \\
\hline $65+$ years, $n(\%)$ & $6827(40.1)$ & $1276(23.9)$ & $<0.001$ & 0.353 \\
\hline Age group,n(\%) & & & $<0.001$ & \\
\hline $18 \sim 49$ years & 5355 (31.4) & $2343(43.8)$ & & 0.258 \\
\hline $50 \sim 59$ years & $3370(19.8)$ & $1277(23.9)$ & & 0.099 \\
\hline $60 \sim 69$ years & $3610(21.2)$ & $1002(18.7)$ & & 0.063 \\
\hline $70+$ years & $4694(27.6)$ & $728(13.6)$ & & 0.351 \\
\hline \multicolumn{5}{|l|}{ Causes of ESRD,n(\%) } \\
\hline CGN,n(\%) & $8037(47.2)$ & $2527(47.2)$ & 0.962 & 0.000 \\
\hline $\mathrm{DN}, \mathrm{n}(\%)$ & $3523(20.7)$ & $468(8.7)$ & $<0.001$ & 0.344 \\
\hline HTN,n(\%) & $1343(7.9)$ & $440(8.2)$ & 0.426 & 0.251 \\
\hline PKD,n(\%) & $766(4.5)$ & $126(2.4)$ & $<0.001$ & 0.115 \\
\hline Other/Unknown,n(\%) & $3360(19.7)$ & $1789(33.4)$ & $<0.001$ & 0.314 \\
\hline \multicolumn{5}{|l|}{ Comorbid conditions,n(\%) } \\
\hline $\mathrm{DM}, \mathrm{n}(\%)$ & $958(5.6)$ & $270(5.0)$ & 0.105 & 0.027 \\
\hline$C V D, n(\%)$ & 3606 (21.2) & $949(17.7)$ & $<0.001$ & 0.089 \\
\hline Malignancy,n(\%) & $734(4.3)$ & $90(1.7)$ & $<0.001$ & 0.153 \\
\hline Chronic liver disease,n(\%) & $870(5.1)$ & $267(5.0)$ & 0.731 & 0.005 \\
\hline COPD,n(\%) & $128(0.8)$ & $20(0.4)$ & $<0.05$ & 0.052 \\
\hline Gastrointestinal ulcer,n(\%) & $90(0.5)$ & $28(0.5)$ & 0.964 & 0.000 \\
\hline
\end{tabular}


Table 2 Baseline characteristics for the propensity scorematched cohort

\begin{tabular}{llll}
\hline Baseline Characteristics & $\mathrm{HD}(\boldsymbol{n}=5350)$ & $\mathrm{PD}(\boldsymbol{n}=5350)$ & $\boldsymbol{P}$-value \\
\hline Gender,n(\%) & $2916(54.5)$ & $2868(53.6)$ & 0.352 \\
Age (years) & $53 \pm 15$ & $53 \pm 15$ & 0.874 \\
65+ years,n(\%) & $1283(24.0)$ & $1276(23.9)$ & 0.874 \\
Age group,n(\%) & & & 0.4 \\
18 49 years & $2352(44.0)$ & $2343(43.8)$ & \\
50 59years & $1261(23.6)$ & $1277(23.9)$ & \\
60 69years & $957(17.9)$ & $1002(18.7)$ & \\
70+ years & $780(14.6)$ & $728(13.6)$ & \\
Causes of ESRD,n(\%) & & & \\
CGN,n(\%) & $2541(47.5)$ & $2527(47.2)$ & 0.786 \\
DN,n(\%) & $477(8.9)$ & $468(8.7)$ & 0.759 \\
HTN,n(\%) & $438(8.2)$ & $440(8.2)$ & 0.944 \\
PKD,n(\%) & $125(2.3)$ & $126(2.4)$ & 0.949 \\
Other/Unknown,n(\%) & $1769(33.1)$ & $1789(33.4)$ & 0.682 \\
Comorbid conditions,n(\%) & & & \\
DM,n(\%) & $260(4.9)$ & $270(5.0)$ & 0.656 \\
CVD,n(\%) & $931(17.4)$ & $949(17.7)$ & 0.647 \\
Malignancy,n(\%) & $85(1.6)$ & $90(1.7)$ & 0.703 \\
Chronic liver disease,n(\%) & $268(5.0)$ & $267(5.0)$ & 0.965 \\
COPD,n(\%) & $22(0.4)$ & $20(0.4)$ & 0.757 \\
Gastrointestinal ulcer,n(\%) & $24(0.4)$ & $28(0.5)$ & 0.578 \\
\hline
\end{tabular}

Demographic characteristics, comorbidity were analyzed using Cox proportional hazard models (forward stepwise, probability remove: 0.1 ) to identify independent mortality risk factors. Table 4 presents a summary of analytical results, HD (vs. PD) was associated with an increased risk for morality with an AHR of 1.140 (95\%CI: 1.023-1.271). Age, diabetic nephropathy (DN), other/unknown causes of ESRD (including lupus nephritis, interstitial nephritis, Hepatitis B Virus associated glomerulonephritis and so on), and patients with comorbid conditions, such as a history of diabetes, CVD or malignancy had increased overall mortality (Table 4.).

Table 3 Survival rate among ESRD patients by follow-up year in the whole cohort and propensity score-matched corhort

\begin{tabular}{|c|c|c|c|c|}
\hline \multirow{2}{*}{$\begin{array}{l}\text { Follow- } \\
\text { up } \\
\text { duration, } \\
\text { year }\end{array}$} & \multicolumn{2}{|c|}{ Whole Cohort } & \multicolumn{2}{|c|}{ Macthed Cohort } \\
\hline & $\overline{\mathrm{HD}}(\%)$ & $\overline{P D(\%)}$ & $\overline{\mathrm{HD}}(\%)$ & $\mathrm{PD}(\%)$ \\
\hline 1 & 93.4 & 96.6 & 95.4 & 96.6 \\
\hline 2 & 86.8 & 91.5 & 90.4 & 91.5 \\
\hline 3 & 80.6 & 87.2 & 86.1 & 87.2 \\
\hline 4 & 74.7 & 83.4 & 81.8 & 83.4 \\
\hline 5 & 69.4 & 78.4 & 77.1 & 78.4 \\
\hline
\end{tabular}

\section{Subgroup analyses according to baseline covariates}

We stratified the matched cohort into subgroups according to various baseline covariates. As shown in Fig. 3 (Risk for all-cause mortality associated with initial dialysis modality for difference subgroups (matched cohort)), this increased mortality risk associated with HD was constant across some subgroups (male and younger age). HD patients with arteriovenous fistula (AVF) had a similar survival rate with PD patients, but HD patients with catheters had a poor survival outcome (Fig. 4. KaplanMeier survival curves for all-cause mortality for HD patients with arteriovenous fistula (AVF) or catheters (Cat), versus PD patients (matched cohort)).

Patients with or without DM did not show statistically significant differences in survival between $\mathrm{HD}$ and PD group. Then, we further stratified them into younger $(<$ 65 years old) and older group ( $\geq 65$ years old). KaplanMeier method with log-rank test revealed that elderly patients with DM were associated with lower survival (Fig. 5. Kaplan-Meier survival curve according to the initial dialysis modality and diabetes mellitus (DM) (matched cohort)), the Cox proportional hazard model showed that the survival of nondiabetic patients younger than 65 years subgroup was better on PD (HD vs PD HR: $1.194,95 \%$ CI: $1.093 \sim 1.305, P<0.001$ ) (Fig. 6. Risk for all-cause mortality associated with initial dialysis modality for diabetes subgroups (matched cohort)).

\section{Discussion}

In this study of ESRD patients initiating dialysis, the allcause mortality was higher in HD patients than that in PD patients in the whole cohort and propensity scorematched cohort. In the adjusted Cox model of time to mortality of the matched cohort, age, DN, other/unknown causes of ESRD, history of DM, CVD and malignancy were independent predictors of mortality. To our knowledge, this is the first large-scale study that uses PSM in a survival comparison of incident PD patients versus $H D$ patients in China.

Our study demonstrated that HD was associated with an increased risk for all-cause mortality compared with PD in the matched cohort (HR 1.140, 95\%CI: 1.023 1.271), which is similar with some previous researches from many countries, such as the United States, India and Korea [22-24]. The survival benefit of PD over HD is obvious in the first 1-2 years of dialysis treatment. Researches from Canada and Denmark showed that PD patients had a lower mortality than HD patients in the first 2 years after initiation of dialysis [10, 25]. There are several reasons to explain why ESRD patients favorite PD as the initiating therapy. Earlier studies are typically based on the late 1990s and early 2000s, and technological progress of $\mathrm{HD}$ and $\mathrm{PD}$ has accelerated during the last decades, especially after the "PD First" policy 


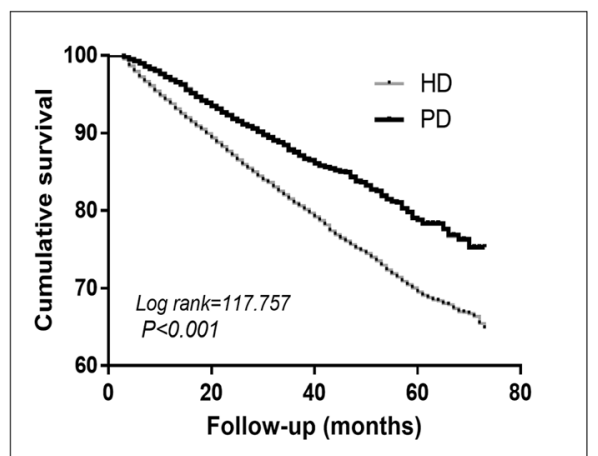

(a). the number at risk below the graph.

\begin{tabular}{cccccc}
\multirow{2}{*}{ Groups } & \multicolumn{5}{c}{ Follow-up (months) } \\
\cline { 2 - 6 } & 0 & 20 & 40 & 60 & 72 \\
\hline HD & 17029 & 12089 & 5553 & 1742 & 100 \\
PD & 5350 & 3789 & 1603 & 370 & 13 \\
\hline
\end{tabular}

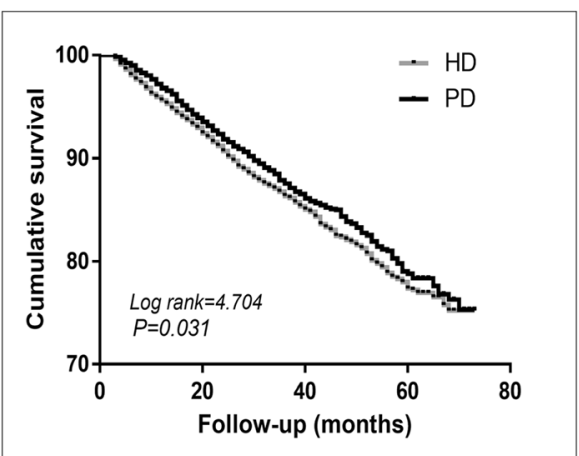

(b). the number at risk below the graph.

\begin{tabular}{cccccc}
\hline \multirow{2}{*}{ Groups } & \multicolumn{5}{c}{ Follow-up (months) } \\
\cline { 2 - 6 } & 0 & 20 & 40 & 60 & 72 \\
\hline HD & 5350 & 3909 & 1898 & 646 & 44 \\
PD & 5350 & 3789 & 1603 & 370 & 13 \\
\hline
\end{tabular}

Fig. 2 a Kaplan-Meier survival curve according to the initial dialysis modality (whole cohort); log-rank test, $P<0.001$. b Kaplan-Meier survival curve according to the initial dialysis modality (matched cohort); log-rank test, $P=0.031$

innovated into PD care [26], which makes tremendous contributions to the PD patients' longevity. The apparent survival advantage of PD may also be due to a lower comorbidity and a lower burden of acute onset ESRD at the inception of dialysis. In our study, HD patients were older, had more comorbidities than PD patients at the enrollment, whom inclined to choose urgent-start HD in order to balance their inner environment as soon as possible. Urgent-start HD patients with central catheter as an initial vascular access had a relation with higher mortality [27], which could promote vascular endothelial damage, lead to inflammatory reaction and increase the chance for infection. Garcia-Canton $\mathrm{C}$, et al. had revealed that HD patients with central catheter had the lowest survival rate, however, patients with AVF had a comparable survival rate with PD patient [28], which was also observed in our study. Compared with HD, PD

Table 4 Risk for all-cause mortality using matched cohort

\begin{tabular}{lllll}
\hline Characteristics & $\beta$ & AHR & $95 \% \mathrm{Cl}$ & $\boldsymbol{P}$-value \\
\hline HD:PD & .131 & 1.140 & $1.023 \sim 1.271$ & $<0.05$ \\
Age & .049 & 1.050 & $1.046 \sim 1.055$ & $<0.001$ \\
Causes of ESRD & & & & $<0.001$ \\
$\quad$ DN & .738 & 2.091 & $1.774 \sim 2.465$ & $<0.001$ \\
HTN & .185 & 1.203 & $0.998 \sim 1.45$ & .052 \\
PKD & -.134 & .874 & $0.575 \sim 1.329$ & .529 \\
$\quad$ Other/Unknown & .371 & 1.449 & $1.274 \sim 1.65$ & $<0.001$ \\
Comorbid conditions & & & & $<0.001$ \\
$\quad$ DM & .283 & 1.328 & $1.084 \sim 1.626$ & $<0.05$ \\
CVD & .221 & 1.247 & $1.099 \sim 1.415$ & $<0.001$ \\
Malignancy & 1.301 & 3.673 & $2.893 \sim 4.663$ & $<0.001$ \\
\hline
\end{tabular}

Multivariable Cox proportional hazards model, adjusted for age, gender, cause of the ESRD, diabetes, history of cardiocerebral vascular diseases, COPD,

gastrointestinal ulcer, chronic liver disease and malignancy has a smaller effect on hemodynamics and fewer dietary restrictions [29], could protect the residual renal function, which is an independent protective factor in survival of ESRD patients [30]. Moreover, when PD patients have technique fail, it is more common for them to switch to HD, therefore their mortality rate was lower than HD patients.

In a subgroup analysis of our matched cohort, male or younger patients of initiating with PD exhibited a significant better survival versus those initiating with HD. This changing may be due to PD technique is relatively easy and has a lower prevalence of preexisting CVD at the initiation of dialysis therapy at a younger age. Particularly in nondiabetic patients aged less than 65 years after adjustment of covariates, initiating with PD was associated with a significantly lower mortality compared with HD. This finding is similar to results from Netherlands, USA, Columbia and Korea, which reported a lower mortality in younger nondiabetic ESRD patients initiating with PD versus HD [22, 24, 31, 32]. Previous studies suggested that PD patients were with higher blood lipid level than HD patients, which might accelerate the process of arteriosclerosis and increase incidences of cardiovascular events [33]. In addition, diabetic patients are easy to be involved with disorders of lipid metabolism $[34,35]$, and PD therapy may affect blood glucose of ESRD patients [36, 37]. Thus, PD was associated with significant higher survival compared with HD in younger without diabetic subgroup.

This study has several limitations worth mentioning. First, this is an retrospective observational study and PSM can only account for observed confounders without any account for unobserved confounders. Therefore, this study may not be completely free of bias due to confounding, because the initial RRT was not randomly 


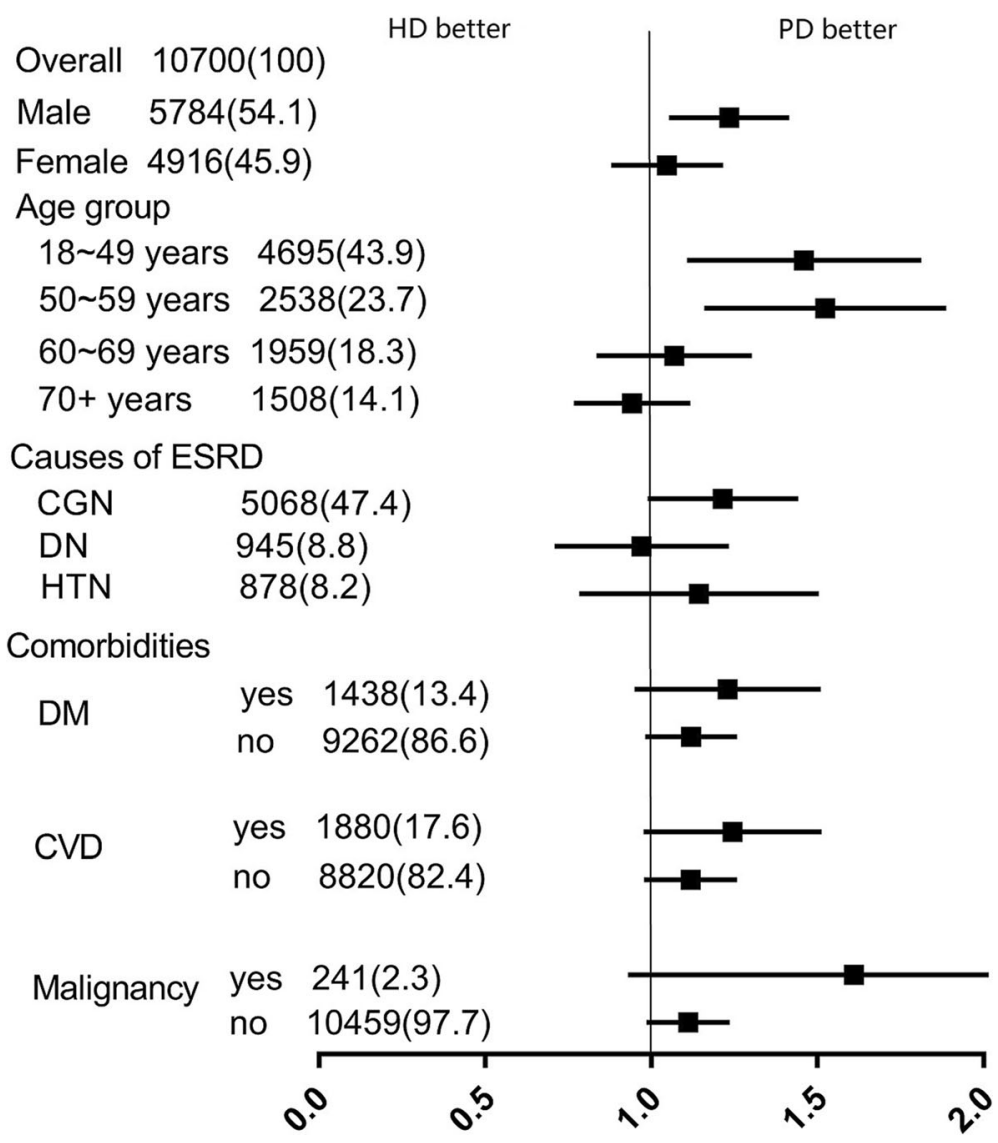

Fig. 3 Risk for all-cause mortality associated with initial dialysis modality for difference subgroups (matched cohort)

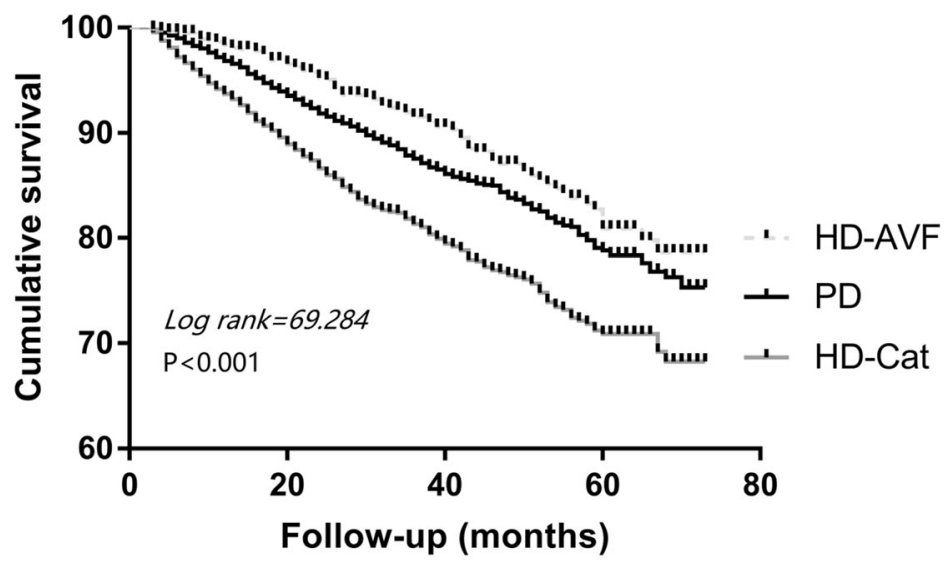

the number at risk below the graph.

\begin{tabular}{cccccc}
\hline \multirow{2}{*}{ Groups } & \multicolumn{5}{c}{ Follow-up (months) } \\
\cline { 2 - 6 } & 0 & 20 & 40 & 60 & 72 \\
\hline HD-AVF & 756 & 609 & 367 & 134 & 9 \\
HD-Cat & 2403 & 1651 & 680 & 201 & 8 \\
PD & 5350 & 3789 & 1603 & 370 & 13 \\
\hline
\end{tabular}

Fig. 4 Kaplan-Meier survival curves for all-cause mortality for HD patients with arteriovenous fistula (AVF) or catheters (Cat), versus PD patients (matched cohort) 


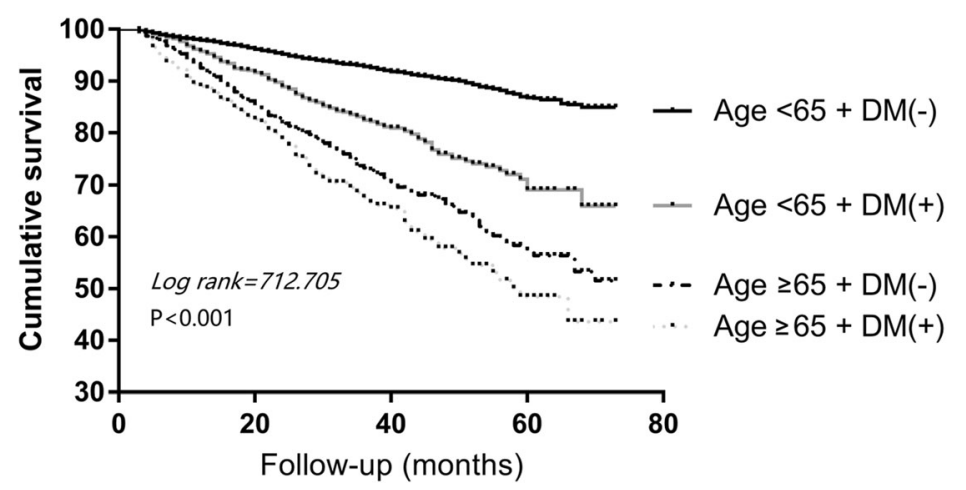

\begin{tabular}{cccccc}
\multicolumn{6}{c}{ the number at risk below the graph. } \\
\cline { 2 - 6 } Groups & 0 & 20 & 40 & 60 & 72 \\
\hline Age $\geq 65+$ DM(+) & 491 & 310 & 111 & 25 & 1 \\
Age $\geq 65+$ DM(-) & 2068 & 1369 & 534 & 120 & 5 \\
Age $<65+$ DM(+) & 947 & 687 & 300 & 70 & 3 \\
Age $<65+$ DM(-) & 7194 & 5332 & 2556 & 801 & 48 \\
\hline
\end{tabular}

Fig. 5 Kaplan-Meier survival curve according to the initial dialysis modality and diabetes mellitus (DM) (matched cohort)

allocated, causality cannot be demonstrated as in the experimental design of a randomized controlled study. Second, we stopped follow-up till the occurrence of censorship for those events in which the patient was alive but could not conclude the follow-up period, which includes kidney transplant and change of dialysis modality. The effect of switching the type of RRT in time- dependent models and more patients switched from PD to HD than from HD to PD was not considered. Third, we could not ascertain the severity of comorbidities because the data were extracted from a database, for example, we cannot calculate the Charlson Comorbidity Index (CCI) in our study. Fourth, this is a retrospective study, several important laboratory characteristics are

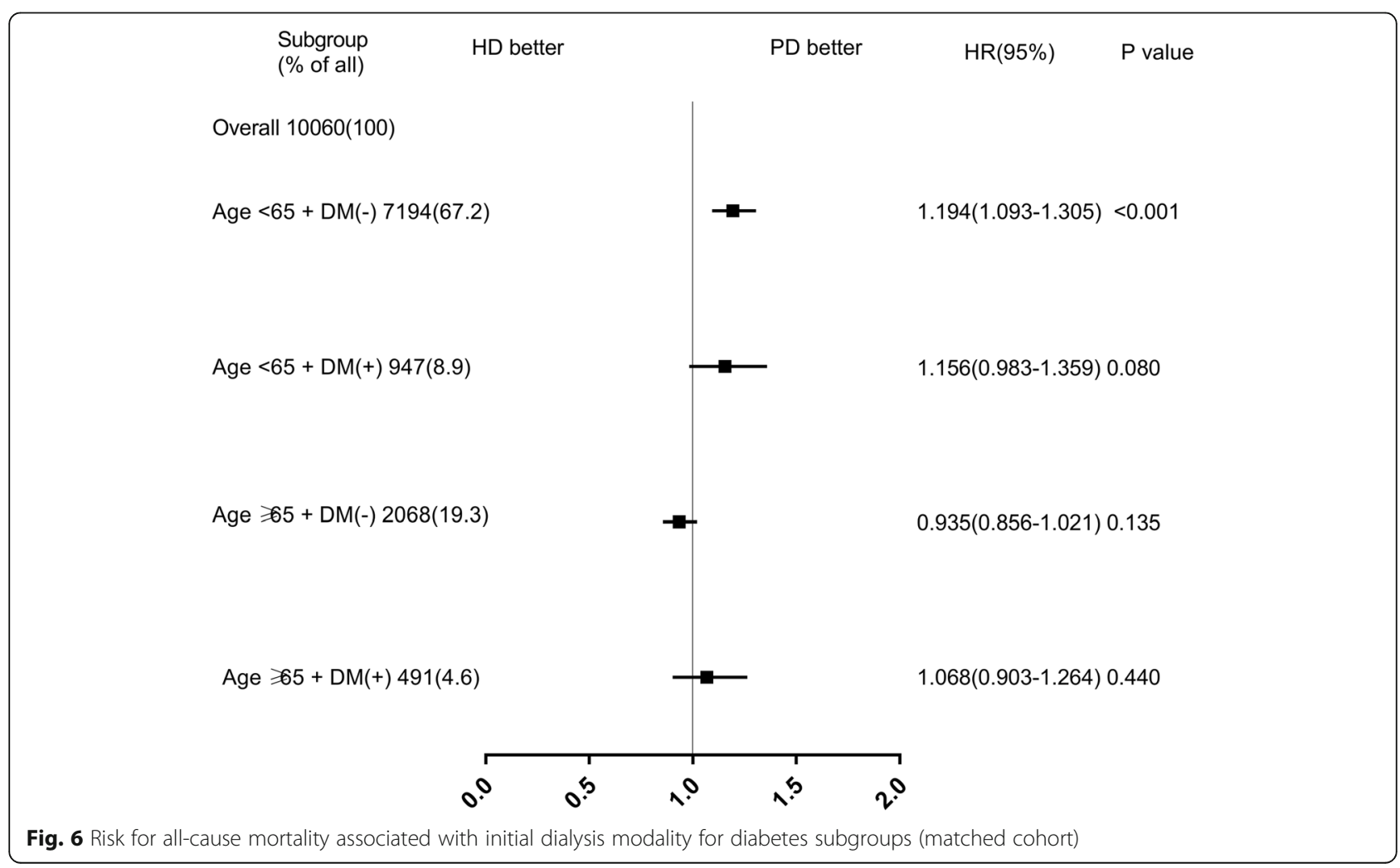


not available in the database, such as residual renal function, $\mathrm{Kt} / \mathrm{V}$ and $\mathrm{iPTH}$.

Despite these limitations, strengths of our study include the large study population that allowed us to assemble the largest PSM cohort of Chinese patients with ESRD initiating with either PD or HD. And this study may have clinically relevant features and may help doctors and patients to make proper dialytic modality choices in Zhejiang province.

\section{Conclusions}

ESRD patients who initiated dialysis with PD yielded superior survival rates compared to HD. Thus, increased use of PD should be given greater consideration when initiating RRT in Chinese population.

\section{Supplementary information}

Supplementary information accompanies this paper at https://doi.org/10. 1186/s12882-020-01909-3.

Additional file 1: Table S1. Baseline characteristics of 7761 excluded hemodialysis (HD) and 541 excluded peritoneal dialysis (PD) patients.

\section{Abbreviations}

PD: Peritoneal dialysis; HD: Hemodialysis; ESRD: End stage renal disease; PSM: Propensity score matching; ZJRDS: Zhejiang Renal Disease System; CKD: Chronic kidney disease; RRT: Renal replacement therapy;

CVD: Cardiovascular diseases; COPD: Chronic obstructive pulmonary disease; HR: Hazard ratio; Cl: Confidence interval; AVF: Arteriovenous fistula; CAPD: Continuous ambulatory peritoneal dialysis; IPD: Intermittent peritoneal dialysis; DM: Diabetes mellitus; DN: Diabetic nephropathy; HTN: Hypertensive nephropathy; CGN: Chronic glomerulonephritis; PKD: Polycystic kidney disease

\section{Acknowledgements}

The authors declare no conflict of interest, thank all doctors, nursing staff and IT engineers of the ZJRDS database for their excellent assistance in registering data from ESRD patients in from 226 hemodialysis centers and 92 peritoneal dialysis centers all over the Zhejiang Province. And thank the ESAO-IFAO-Congress 2017 for accepting the abstract of this manuscript in oral format at the 44th ESAO and 7th IFAO Congress in Vienna, Austria (Sep 6-9, 2017) and awarding Yao Xi with an IFAO Transcontinental Travel Scholarship of the Congress. (http://www.esao2017.org/index.php/awards/).

\section{Authors' contributions}

Concept/design and drafting of article by $Y X$, data collection by LWH, SN and DXY, data analysis/interpretation/statistics by YX and LWQ, critical revision of article by $\mathrm{ZP}$ and $\mathrm{CJH}$. All authors have read and approved the manuscript.

\section{Funding}

This project was supported by a grant from Prof. Zhang Ping's Special Scientific Research Fund of Public Welfare Profession from National Health and Family Planning Commission of China (No. 201502010), Pro. Chen Jianghua's National Key Research and Development Project (No. 2018YFC1214003) and Prof. Lin Weiqiang's National Natural Science foundation of China (No. 81670651). These funds were used to maintain the ZJRDS database operation, update the statistical software and pay patients follow-up fee.

\section{Availability of data and materials}

Data were from Zhejiang Renal Disease System (ZJRDS) database (http:// zjdialysis.com/ZK/web-index!showIndex.action).

\section{Ethics approval and consent to participate}

This study was performed in accordance with the Declaration of Helsinki and approved by the Research Ethics Committee of the First Affiliated Hospital, College of Medicine, Zhejiang University, and the ethics number is 2014368 and the date of registration is December 30th, 2014. All participants provided written informed consent before enrollment.

\section{Consent for publication}

Not Applicable.

\section{Competing interests}

The authors declare that they have no competing interests.

\section{Author details}

'Kidney Disease Center, The First Affiliated Hospital, College of Medicine, Zhejiang University, No.79 Qingchun Road, Hangzhou 310003, Zhejiang Province, China. ${ }^{2}$ Key Laboratory Of Nephropathy, Hangzhou, Zhejiang, China.

Received: 18 April 2019 Accepted: 25 June 2020

Published online: 29 July 2020

\section{References}

1. Puddu PE, Piras P, Menotti A. Competing risks and lifetime coronary heart disease incidence during 50years of follow-up. Int J Cardiol. 2016;219:79-83.

2. Kramer A, Pippias M, Noordzij M, Stel VS, Andrusev AM, Aparicio-Madre MI, Arribas Monzon FE, Asberg A, Barbullushi M, Beltran P, et al. The European renal association - European Dialysis and transplant association (ERA-EDTA) registry annual report 2016: a summary. Clin Kidney J. 2019;12(5):702-20.

3. van Eck van der Sluijs A, Bonenkamp AA, Dekker FW. Abrahams AC, van Jaarsveld BC, group ds: Dutch nOcturnal and hoME dialysis study to improve clinical outcomes (DOMESTICO): rationale and design. BMC Nephrol. 2019;20(1):361

4. Lin E, Cheng XS, Chin KK, Zubair T, Chertow GM, Bendavid E, Bhattacharya J. Home Dialysis in the prospective payment system era. J Am Soc Nephrol. 2017;28(10):2993-3004

5. Erickson KF, Zhao B, Ho V, Winkelmayer WC. Employment among patients starting Dialysis in the United States. Clin J Am Soc Nephrol. 2018;13(2):265-73.

6. Wu B, Wang M, Gan L, Zhao H. Comparison of patient survival between hemodialysis and peritoneal dialysis in a single Chinese center. Int Urol Nephrol. 2014;46(12):2403-7.

7. Beladi Mousavi SS, Hayati F, Valavi E, Rekabi F, Mousavi MB. Comparison of survival in patients with end-stage renal disease receiving hemodialysis versus peritoneal dialysis. Saudi J Kidney Dis Transpl. 2015;26(2):392-7.

8. Yang F, Khin LW, Lau T, Chua HR, Vathsala A, Lee E, Luo N. Hemodialysis versus peritoneal Dialysis: a comparison of survival outcomes in south-east Asian patients with end-stage renal disease. PLoS One. 2015;10(10): e0140195.

9. Waldum-Grevbo B, Leivestad T, Reisaeter AV, Os I. Impact of initial dialysis modality on mortality: a propensity-matched study. BMC Nephrol. 2015;16: 179.

10. Yeates K, Zhu N, Vonesh E, Trpeski L, Blake P, Fenton S. Hemodialysis and peritoneal dialysis are associated with similar outcomes for end-stage renal disease treatment in Canada. Nephrol Dial Transplant. 2012;27(9):3568-75.

11. Jiwakanon S, Chiu YW, Kalantar-Zadeh K, Mehrotra R. Peritoneal dialysis: an underutilized modality. Curr Opin Nephrol Hypertens. 2010;19(6):573-7.

12. Mehrotra R. Choice of dialysis modality. Kidney Int. 2011;80(9):909-11.

13. Chiu YW, Jiwakanon S, Lukowsky L, Duong U, Kalantar-Zadeh K, Mehrotra R. An update on the comparisons of mortality outcomes of hemodialysis and peritoneal dialysis patients. Semin Nephrol. 2011;31(2):152-8.

14. Kim H, Kim KH, Park K, Kang SW, Yoo TH, Ahn SV, Ahn HS, Hann HJ, Lee S, Ryu JH, et al. A population-based approach indicates an overall higher patient mortality with peritoneal dialysis compared to hemodialysis in Korea. Kidney Int. 2014;86(5):991-1000.

15. Liu ZH. Nephrology in China. Nat Rev Nephrol. 2013;9(9):523-8.

16. Helenius K, Longford N, Lehtonen L, Modi N, Gale C. Neonatal data analysis $U$, the United Kingdom neonatal C: association of early postnatal transfer and birth outside a tertiary hospital with mortality and severe brain injury in extremely preterm infants: observational cohort study with propensity score matching. BMJ. 2019;367:15678. 
17. Montaigne D, Marechal X, Modine T, Coisne A, Mouton S, Fayad G, Ninni S, Klein C, Ortmans $S$, Seunes C, et al. Daytime variation of perioperative myocardial injury in cardiac surgery and its prevention by rev-Erbalpha antagonism: a single-Centre propensity-matched cohort study and a randomised study. Lancet. 2018;391(10115):59-69.

18. Edner M, Benson L, Dahlstrom U, Lund LH. Association between reninangiotensin system antagonist use and mortality in heart failure with severe renal insufficiency: a prospective propensity score-matched cohort study. Eur Heart J. 2015;36(34):2318-26.

19. Yamanouchi M, Furuichi K, Hoshino J, Toyama T, Hara A, Shimizu M, Kinowaki K, Fujii T, Ohashi K, Yuzawa Y, et al. Nonproteinuric versus Proteinuric phenotypes in diabetic kidney disease: a propensity scorematched analysis of a nationwide, biopsy-based cohort study. Diabetes Care. 2019;42(5):891-902

20. Schrage B, Uijl A, Benson L, Westermann D, Stahlberg M, Stolfo D, Dahlstrom U, Linde CM, Braunschweig F, Savarese G. Association between use of primary prevention implantable Cardioverter-defibrillators and mortality in patients with heart failure: a prospective propensity-score matched analysis from the Swedish heart failure registry. Circulation. 2019; 140(19):1530-9.

21. Danial P, Hajage D, Nguyen LS, Mastroianni C, Demondion P, Schmidt M, Bougle A, Amour J, Leprince P, Combes A, et al. Percutaneous versus surgical femoro-femoral veno-arterial ECMO: a propensity score matched study. Intensive Care Med. 2018;44(12):2153-61.

22. Weinhandl ED, Foley RN, Gilbertson DT, Arneson TJ, Snyder JJ, Collins AJ. Propensity-matched mortality comparison of incident hemodialysis and peritoneal dialysis patients. J Am Soc Nephrol. 2010;21(3):499-506.

23. Makkar V, Kumar M, Mahajan R, Khaira NS. Comparison of outcomes and quality of life between hemodialysis and peritoneal Dialysis patients in Indian ESRD population. J Clin Diagn Res. 2015:9(3):OC28-31.

24. Ryu JH, Kim H, Kim KH, Hann HJ, Ahn HS, Lee S, Kim SJ, Kang DH, Choi KB, Ryu DR. Improving survival rate of Korean patients initiating dialysis. Yonse Med J. 2015;56(3):666-75.

25. Heaf JG, Lokkegaard $H$, Madsen M. Initial survival advantage of peritoneal dialysis relative to haemodialysis. Nephrol Dial Transplant. 2002;17(1):112-7.

26. Heaf JG, Wehberg S. Relative survival of peritoneal dialysis and haemodialysis patients: effect of cohort and mode of dialysis initiation. PLoS One. 2014;9(3):e90119.

27. Polkinghorne KR, McDonald SP, Atkins RC, Kerr PG. Vascular access and allcause mortality: a propensity score analysis. J Am Soc Nephrol. 2004;15(2): 477-86.

28. Garcia-Canton C, Rufino-Hernandez JM, Vega-Diaz N, Perez-Borges P, BoschBenitez-Parodi E, Saavedra P, Garcia-Gomez C, Marrero-Robayna S, MaceiraCruz B, Rodriguez-Perez JC, et al. A comparison of medium-term survival between peritoneal dialysis and haemodialysis in accordance with the initial vascular access. Nefrologia. 2013;33(5):629-39.

29. Plantinga LC, Fink NE, Levin NW, Jaar BG, Coresh J, Levey AS, Klag MJ, Powe NR. Early, intermediate, and long-term risk factors for mortality in incident dialysis patients: the choices for healthy outcomes in caring for ESRD (CHOICE) study. Am J Kidney Dis. 2007;49(6):831-40.

30. Shemin $D$, Bostom AG, Laliberty $P$, Dworkin LD. Residual renal function and mortality risk in hemodialysis patients. Am J Kidney Dis. 2001;38(1):85-90.

31. Sanabria M, Munoz J, Trillos C, Hernandez G, Latorre C, Diaz CS, Murad S, Rodriguez K, Rivera A, Amador A, et al. Dialysis outcomes in Colombia (DOC) study: a comparison of patient survival on peritoneal dialysis vs hemodialysis in Colombia. Kidney Int Suppl. 2008;108:S165-72.

32. Liem YS, Wong JB, Hunink MG, de Charro FT, Winkelmayer WC. Comparison of hemodialysis and peritoneal dialysis survival in the Netherlands. Kidney Int. 2007;71(2):153-8

33. Kronenberg F, Lingenhel A, Neyer U, Lhotta K, Konig P, Auinger M, Wiesholzer M, Andersson H, Dieplinger $H$. Prevalence of dyslipidemic risk factors in hemodialysis and CAPD patients. Kidney Int Suppl. 2003; 84:S113-6.

34. Tonelli M, Muntner P, Lloyd A, Manns BJ, Klarenbach S, Pannu N, James MT, Hemmelgarn BR. Alberta kidney disease N: risk of coronary events in people with chronic kidney disease compared with those with diabetes: a population-level cohort study. Lancet. 2012;380(9844):807-14.

35. Fox CS, Matsushita K, Woodward M, Bilo HJ, Chalmers J, Heerspink HJ, Lee BJ, Perkins RM, Rossing P, Sairenchi T, et al. Associations of kidney disease measures with mortality and end-stage renal disease in individuals with and without diabetes: a meta-analysis. Lancet. 2012;380(9854):1662-73.
36. Huang CC, Cheng KF, Wu HD. Survival analysis: comparing peritoneal dialysis and hemodialysis in Taiwan. Perit Dial Int. 2008;28(Suppl 3):S15-20.

37. Winkelmayer WC, Glynn RJ, Mittleman MA, Levin R, Pliskin JS, Avorn J. Comparing mortality of elderly patients on hemodialysis versus peritoneal dialysis: a propensity score approach. J Am Soc Nephrol. 2002;13(9):2353-62.

\section{Publisher's Note}

Springer Nature remains neutral with regard to jurisdictional claims in published maps and institutional affiliations.
Ready to submit your research? Choose BMC and benefit from:

- fast, convenient online submission

- thorough peer review by experienced researchers in your field

- rapid publication on acceptance

- support for research data, including large and complex data types

- gold Open Access which fosters wider collaboration and increased citations

- maximum visibility for your research: over $100 \mathrm{M}$ website views per year

At BMC, research is always in progress.

Learn more biomedcentral.com/submissions 